\title{
Comportamiento clínico y costos de la gastroenteritis por rotavirus en lactantes: Adquisición comunitaria versus nosocomial
}

\author{
Luis Delpiano M., Joel Riquelme R, M. Cristina Casado F. y Ximena Álvarez H.
}

\section{Clinical features and costs of rotavirus gastroenteritis in infants: community versus nosocomialy acquired infection}

This is a prospective 12 month (July 2003-June 2004) cohort study in one large tertiary hospital of Santiago, Chile aimed to describe clinic features and calculate the direct costs of hospitalization associated to community-acquired $(n=78)$ and nosocomially-acquired $(n=52)$ rotavirus infection. A gastroenteritis severity score after Rennels 1996, (0 to 17 points) was applied and costs where calculated based on those assigned by the Chilean National Funds for Health (FONASA). Severe gastroenteritis manifested by a score $>14$ occurred in $26.9 \%$ and $9.6 \%$ of community and nosocomially-acquired cases respectively $(p<0.015)$. The former had lower bicarbonate levels $(\mathrm{p}<0.001)$, and required more volume expansion compared to the latter $(\mathrm{p}<0.023)$. The average cost was US 277 per case for community acquired rotavirus and US 268 for nosocomial infection. In this hospital the cost of nosocomial rotavirus infection was $\sim$ US\$ 13,900 for a 12 month period. These results should stimulate the implementation of active prevention and control programs.

Key words: nosocomial infections, rotavirus, gastroenteritis.

Palabras claves: infecciones nosocomiales; rotavirus; gastroenteritis.

\section{Introducción}

$\mathrm{L}$ as infecciones intrahospitalarias (IIH) aumentan la morbilidad, costos de atención y mortalidad a la vez que se asocian con prolongación de la estadía hospitalaria ${ }^{1}$. En niños estas infecciones presentan tasas elevadas al considerar etiologías virales respiratorias y gastrointestinales (rotavirus), y habitualmente reflejan la epidemiología estacional de la comunidad ${ }^{2-4}$. Así entonces, la internación de un niño a un centro hospitalario, debido a la vía de transmisión de rotavirus (habitualmente mano portada) y a su relativa facilidad de diseminación intrahospitalaria, conlleva un riesgo de adquisición de una rotavirosis nosocomial ${ }^{5,6}$.

Se sabe que rotavirus causa al año aproximadamente 138 millones de episodios de diarrea, 2 millones de hospitalizaciones y entre 440.000 y 680.000 muertes alrededor del mundo; aproximadamente 1 en 295 niños mueren por esta enfermedad antes de los 5 años ${ }^{8}$. Una vigilancia de consultas médicas de urgencia y hospitalizaciones por rotavirosis entre 1997 y $1998^{9}$ en Chile, mostró que representa $5 \%$ de las consultas y $6 \%$ de las hospitalizaciones en niños bajo 36 meses de edad.

Habitualmente esta infección se presenta antes de los 5 años de vida pero los cuadros de gastroenteritis severa presentan mayor incidencia entre los 3 meses y 3 años de edad ${ }^{10}$. La infección en neonatos pudiese ser asintomática ${ }^{11}$. Existen ocasionales casos sintomáticos entre adultos contactos de menores infectados, aunque con mayor frecuencia ocurre una infección subclínica. Por otro lado, rotavirus aparece como la principal causa de diarrea nosocomial en lactantes y pre escolares ${ }^{12}$ y también se le ha descrito como agente de brotes en guarderías infantiles, identificándose en 25 a $40 \%$ de los brotes de diarrea con tasas de ataque de 40 a $70 \%{ }^{13}$.

Existen factores que dificultan el control institucional de rotavirus: la excreción viral es iniciada antes de la aparición de síntomas, encontrándose partículas virales en deposiciones desde aproximadamente 48 horas antes del inicio del cuadro clínico ${ }^{14}$; un niño infectado elimina 100 billones de partículas virales por gramo de deposición; el virus se elimina en las heces por un promedio de 4 días, pudiendo ser mayor a 30 días en pacientes inmunocomprometidos o en quienes cursan con diarrea severa y excreción viral variable desde 4 a 57 días $^{15}$; rotavirus se propaga por vía fecaloral siendo en niños relevante la contaminación de las manos de sus cuidadores, los fomites o superficies ${ }^{16}$; en
Servicio de Pediatría. Hospital Clínico San Borja Arriarán

Recibido: 04-05-2005 Aceptado: 18-11-2005

Correspondencia a: Luis Delpiano Méndez ludelpia@vtr.net 
lactantes, influye además del frecuente contacto cercano, el uso y la práctica del cambio de pañales, identificándose como de alto riesgo para transmisión; rotavirus se ha encontrado en depósitos de pañales, juguetes, griferías, áreas de cambio de pañales y también de preparación de alimentos, demostrando que este agente se difunde más allá del área directamente contaminada con deposiciones; finalmente, este virus puede sobrevivir días o semanas en superficies ambientales y permanecer viable en las manos hasta por 4 horas ${ }^{17,18}$.

Las tasas reportadas por el MINSAL para diarreas en lactantes varía en los últimos 3 años entre 13 y 0,9 por 100 egresos, siendo rotavirus el principal agente identificado ${ }^{7}$. En el Servicio de Pediatría del Hospital San Borja Arriarán (HSBA) en los últimos 2 años estas tasas se han mantenido por sobre el estándar nacional propuesto por MINSAL.

En conocimiento de las permanentes elevadas tasas de diarrea nosocomial causadas por rotavirus en nuestra institución, a pesar de programas implementados, este estudio tiene como objetivos:

- Describir la epidemiología y expresión clínica de la rotavirosis nosocomial.

- Calcular los costos directos ocasionados en lactantes que cursan con diarrea por rotavirus nosocomial comparando con casos de adquisición comunitaria.

- Generar información que contribuya a motivar los programas de prevención y control de la rotavirosis nosocomial.

\section{Pacientes y Método}

Se efectuó un estudio prospectivo observacional de pacientes pediátricos con diarrea aguda por rotavirus hospitalizados en el Servicio de Pediatría del HSBA. Durante el período comprendido entre julio 1, 2003 y junio 30, 2004 se reclutaron todos los lactantes (0-24 meses) en que se hizo diagnóstico de rotavirosis.

\section{Definiciones}

Diarrea aguda: disminución de la consistencia y aumento de la frecuencia mayor o igual a tres deposiciones por día y por un período menor de 14 días

Rotavirosis: alteración en el contenido de agua, volumen o frecuencia de las deposiciones asociada a un test de rotaforesis en deposiciones positivo, examen realizado en laboratorio del hospital.

Rotavirosis adquirida en la comunidad (Grupo 1): paciente ingresado con diarrea aguda o que la presenta dentro de las primeras 48 horas de internación.

Rotavirosis intrahospitalaria (Grupo 2): aquella iniciada luego de 72 horas desde el ingreso hospitalario.

Test de rotavirus. Las muestras de deposiciones se recolectaron en tubos secos sin preservantes y fueron transportadas al laboratorio. En este lugar fueron sometidas a procesamiento de rotaforesis según indicaciones del proveedor (Departamento de Virología-Universidad de Chile) -técnica empleada originalmente por el grupo de KA Kapikian en $1978^{19}$ - con dilución, electroforesis y tinción de la muestra correspondiente. Se informó como positiva a cualquiera que mostrara al menos las cuatro primeras bandas.

Criterios de exclusión. Pacientes internados en otros servicios pediátricos o con resultado de rotaforesis negativa a pesar de presentar un cuadro clínico compatible.

Registro de datos y estudio de costos. Además de elementos biodemográficos generales, se consignó signos y síntomas (incluido temperatura rectal máxima en las primeras $24 \mathrm{~h}$ ), el total de exámenes de laboratorio solicitados con motivo del episodio mórbido agudo y se aplicó costo económico de acuerdo a arancel FONASA (Fondo Nacional de Salud) de atención cerrada vigente en los años 2003-2004 (Anexo 1). Así también se consignó el número de días de estadía hospitalaria; para el grupo 1 todo su periodo de internación y para el grupo 2 se definió como el número total de días de duración del cuadro diarreico.

A todos los pacientes se les aplicó, luego de finalizado el episodio de diarrea aguda, una escala de gravedad clínico para gastroenteritis por rotavirus, adaptado de M. Rennels ${ }^{20}$ con puntuación de 0 a 17 puntos, y que a su vez corresponde a una modificación de una escala publicada primariamente por Flores en $1987^{21}$ (Anexo 2). Se consideró diarrea leve a aquellos episodios con puntuación igual o menor que 7 , grave con puntuación entre 8 y 13 puntos y con gravedad extrema a todo paciente con puntuación mayor o igual a 14 .

El proyecto se llevó a cabo de acuerdo a las buenas prácticas clínicas y las regulaciones locales, manteniendo la confidencialidad de los pacientes. Fue revisado y aprobado por el Comité de investigación Pediátrica de la Universidad de Chile inserto en el Servicio de Pediatría.

Análisis estadístico. Los datos obtenidos se ingresaron en una base de datos Excel para su posterior análisis, y en ella se calculó promedios, mediana y desviación estándar. Se efectuó pruebas de significación estadística, exigiendo nivel de significación $\alpha=0,05 \mathrm{e}$ incluyó el estudio de significación en el análisis de grupos de datos con proporciones independientes y con dos desviaciones estándar. Se realizó además cálculo de tasas de diarrea nosocomial por rotavirus según egresos y calculó riesgo relativo con IC de 95\%. El plan de análisis de los resultados incluyó la descripción por: sexo, edad, gravedad clínica (laboratorio y escala gravedad), días de estadía hospitalaria. 


\begin{tabular}{|c|c|c|}
\hline \multicolumn{3}{|c|}{$\begin{array}{l}\text { Anexo 1. Arancel costos FONASA* atención cerrada } \\
\text { (pacientes hospitalizados). MINSAL Chile } 2004\end{array}$} \\
\hline Prestación & $\begin{array}{l}\text { Costo unitario en } \\
\text { pesos chilenos }\end{array}$ & $\begin{array}{l}\text { Costo unitario en } \\
\text { dólares americanos }{ }^{* *}\end{array}$ \\
\hline Consulta médica en $\mathrm{S}$. de Urgencia & 8.160 & 15,7 \\
\hline Día hospitalización en sala Pediatría & 23.930 & 46 \\
\hline Hemograma & 1.620 & 3,1 \\
\hline Proteína $\mathrm{C}$ reactiva & 3.300 & 6,3 \\
\hline Gases arteriales- venosos & 2.010 & 3,9 \\
\hline Electrolitos plasmáticos & 660 & 1,3 \\
\hline Glicemia & 710 & 1,4 \\
\hline Nitrógeno ureico & 710 & 1,4 \\
\hline Perfil bioquímico & 4.560 & 8,8 \\
\hline Inmunofluorescencia viral directa & 2.780 & 5,3 \\
\hline Orina completa & 710 & 1,4 \\
\hline Hemocultivo automatizado & 2.280 & 4,4 \\
\hline Coprocultivo & 2.250 & 4,3 \\
\hline Urocultivo & 1.970 & 3,8 \\
\hline Cultivo de LCR & 1.590 & 3,0 \\
\hline Rotaforesis & 2.270 & 4,4 \\
\hline PH - Fehling en deposiciones & 630 & 1,2 \\
\hline $\begin{array}{l}\text { *FONASA: Fondo Nacional de Salud } \\
\text { ** } 1 \text { dólar americano }=520 \text { pesos }\end{array}$ & re 2005) & \\
\hline
\end{tabular}

Anexo 2. Escala de gravedad de gastroenteritis

Signos o síntomas clínicos

Puntos

Duración de diarrea

$<2$ días 1

2 a 4 días 2

$>4$ días 3

$\mathrm{N}^{\circ}$ máximo deposiciones en 24 horas

$4-5$

Duración de vómitos

0 días

1 - 2 días

N máximo de vómitos en 24 horas

1

2

$>3$

Deshidratación

No

Sí

\section{Temperatura}

\section{$<37.6^{\circ} \mathrm{C}$}

$37,6^{\circ} \mathrm{C}-38,6^{\circ} \mathrm{C}$

$>38,6^{\circ} \mathrm{C}$

Total

Adaptado de Rennels (ref 20) en el período de estudio), y de acuerdo a definición previa, se agruparon 78 lactantes en el Grupo 1 y 52 lactantes en el Grupo 2.

Un $42,3 \%$ en el Grupo 1 y $61,5 \%$ en el Grupo 2 eran varones. Hubo $20,5 \%$ en el Grupo 1 y $56,8 \%$ en el Grupo 2 de lactantes bajo 6 meses de edad ( $p<0,0001)$; en el Grupo 1, 79,5\% tenía entre 7 y 24 meses de edad (Tabla 1).

Diagnósticos de ingreso. La totalidad los pacientes en el Grupo 1 ingresó con síndrome diarreico agudo, agregándose el diagnóstico de insuficiencia renal en 2 y varicela en 1 . Dos pacientes $(2,5 \%)$ ingresaron con diarrea disentérica. Un paciente de 1 mes, que ingresó afebril, con concentración plasmática de ${ }^{+} \mathrm{HCO} 3$ de 7 $\mathrm{mEq} / 1$ y que obtuvo puntaje de 11 en escala de gravedad de gastroenteritis, fue atendido transitoriamente en UCIP por shock hipovolémico secundario a deshi- dratación. En el Grupo 2 los diagnósticos que motivaron el ingreso fueron: neumonía, con o sin obstrucción bronquial (30), infección del tracto urinario (9), pleuroneumonías (2), síndrome convulsivo (2), meningitis bacteriana aguda (1), apneas (1), osteoartritis (1), exantema febril (1), cardiopatía descompensada (1), varicela (1), TEC (1), parotiditis crónica recurrente (1) y síndrome de intestino corto (1).

Comportamiento epidemiológico. La incidencia de rotavirosis fue mayor entre noviembre y febrero, para luego mantener una frecuencia promedio no mayor a 5 casos por mes (Figura 1). Hubo un brote nosocomial en los meses de septiembre y octubre, para posterior- 
mente desde noviembre a febrero, y a pesar de un mayor número de ingresos globales, disminuir la incidencia de casos nosocomiales.

Tasas de diarrea nosocomial por rotavirus. Aunque en julio 2003 (primer mes de la vigilancia) no hubo casos identificados, en los restantes meses del año siempre se alcanzaron tasas por sobre el indicador nacional para ese año (1,21 por 100 egresos) (Tabla 2), idéntica situación que se apreció en los meses del año

Tabla 1. Distribución por edad de lactantes con diarrea por rotavirus. Servicio de Pediatría. Hospital Clínico San Borja Arriarán. Julio 2003 a junio $2004(n=130)$

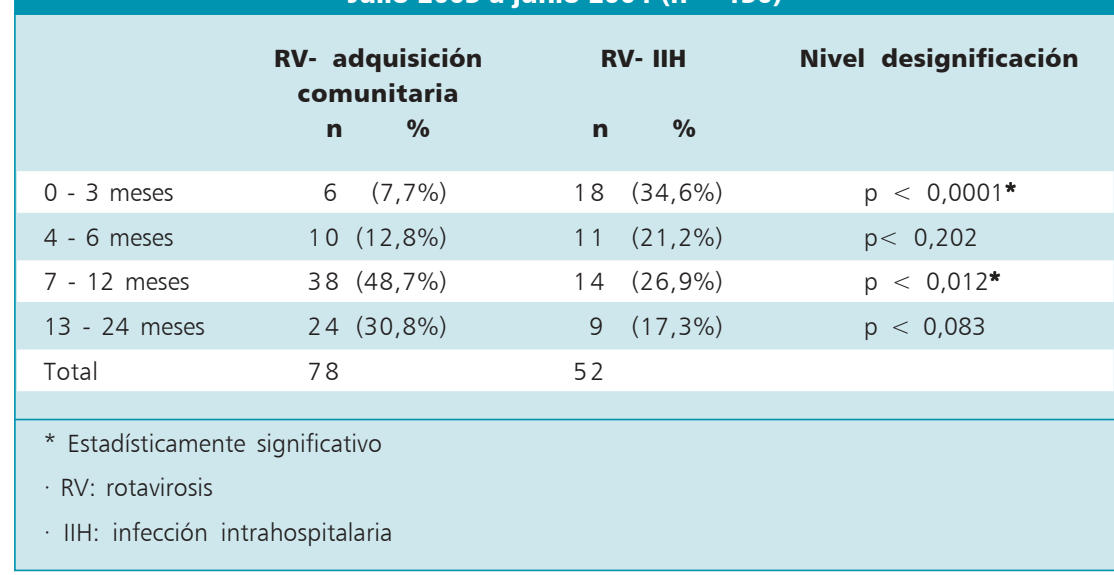

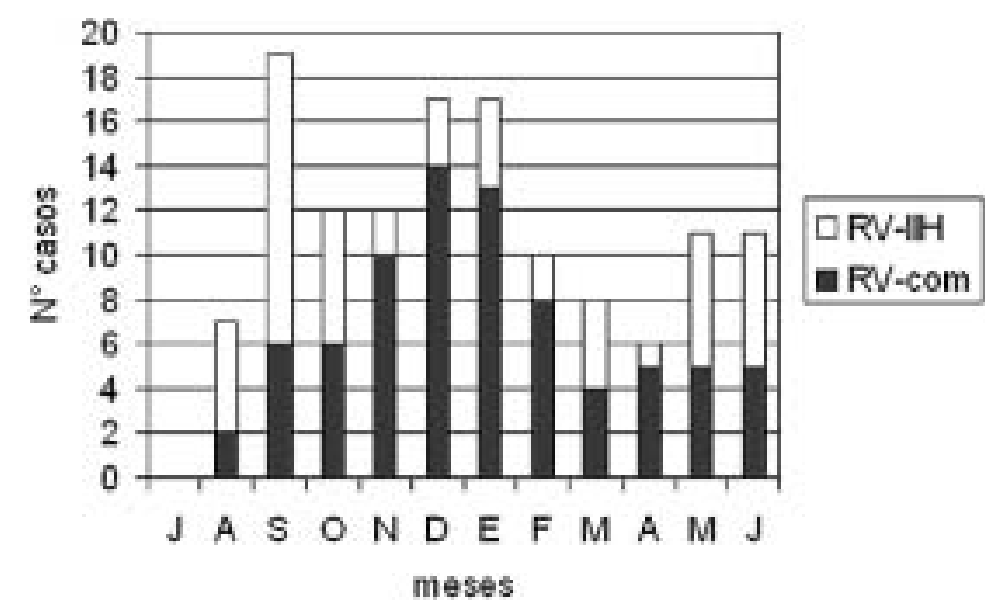

Gráfico 1. Distribución por mes de pacientes con diarrea por rotavirus. Servicio de Pediatría Hospital Clínico San Borja Arriarán. Julio 2003 a junio 2004 (n = 130). RV-IIH: rotavirosis nosocomial; RV-com: rotavirosis de adquisición comunitaria.
2004, cuya tasa MINSAL correspondió a 0,8 por 100 egresos. Luego de un año de vigilancia, la comparación de tasa de diarrea nosocomial por rotavirus en lactantes del Servicio de Pediatría del HSBA, con la tasa propuesta como estándar nacional para el año 2004, entregó un riesgo relativo igual a 2,04 (IC 95\% $0,13-30,2)$.

El inicio del cuadro diarreico por rotavirus en los pacientes del Grupo 2 fue en promedio a los 6,2 días de hospitalización, (56\% de ellos entre 3 y 5 días, $28 \%$ entre 6 y 8 días, y 16\% inició esta morbilidad sobre el noveno día de internación).

Expresión clínica. Los pacientes del Grupo 1 presentaron fiebre durante el primer día de ingreso en promedio de $38,6{ }^{\circ} \mathrm{C}\left(37,2-41^{\circ} \mathrm{C}\right)$, semejante al promedio en el Grupo 2: $38,5^{\circ} \mathrm{C}\left(37-39,7{ }^{\circ} \mathrm{C}\right)$, destacando mayor porcentaje de hipertermia en pacientes del Grupo 1 , con 6 pacientes con temperatura $>$ a $40{ }^{\circ} \mathrm{C}$ versus ningún paciente en el Grupo $2(\mathrm{p}<0,04)$.

Estado ácido base plasmático. El Grupo 1 presentó un valor promedio de $\mathrm{pH}$ sanguíneo de 7,26 y el Grupo 2 7,28 (p NS). Pero la valoración del nivel de ${ }^{+} \mathrm{HCO} 3$ en sangre promedio fue de $14,8 \mathrm{mEq} / 1$ para el Grupo 1 y $19 \mathrm{mEq} / 1$ para el Grupo $2(\mathrm{p}<0,001)$

Gravedad clínica. En este mismo sentido, la aplicación de la escala de evaluación de gravedad de gastroenteritis (Tabla 3) mostró que la mayoría de los pacientes de ambos grupos se concentró en puntajes de diarrea grave ( 8 a 13 puntos) con 55,1 y $67,3 \%$ en los grupos 1 y 2 respectivamente. Al evaluar los lactantes con episodios de gravedad extrema, hubo $26,9 \%$ en el Grupo 1 versus 9,6\% en el Grupo 2 ( $\mathrm{p}<0,015$ ). El promedio de puntaje fue de 11,19 para el Grupo 1 y 9,98 para el Grupo $2(\mathrm{p}<0,047)$.

Los lactantes que presentaron shock hipovolémico y/o necesitaron de expansión de volumen por deshidratación o inestabilidad hemodinámica fueron $20(25,6 \%)$ en el Grupo 1 y $5(9,6 \%)$ en el Grupo 2 (p < 0,023). No fue indicada hidratación parenteral en $46,2 \%$ de lactantes del Grupo 2 versus 2,6\% en el Grupo 1 ( $\mathrm{p}<0,001$ ). Además 42,3\% de los pacientes en el Grupo 1 requirieron hidratación por fleboclisis durante 1 a 2 días y $46,1 \%$ por 3 a 4 días, a diferencia del Grupo 2 donde $17,3 \%$ recibió esta hidratación intravenosa por 3 a 4 días $(\mathrm{p}<0,007)$.

La estadía hospitalaria de los pacientes del Grupo 1 alcanzó en promedio a 4,8 días por paciente a diferencia de los 5,2 días promedio de estadía a causa de la diarrea nosocomial por rotavirus en el Grupo 2 ( $p$ NS).

Otros hallazgos en la evolución de estos pacientes, mostraron que en el Grupo 1, dos pacientes adquirieron una infección respiratoria viral nosocomial (VRS y VPI), y en otro se pesquisó bacteriemia por Klebsiella pneumoniae. En el Grupo 2, uno se presentó con dia- 
rrea disentérica, y además del cuadro nosocomial que motivó el ingreso a este protocolo, 2 también cursaron infección respiratoria viral (ADV y VPI) y otros 2 lactantes cursaron con infección urinaria intrahospitalaria por Escherichia coli y Candida albicans respectivamente. Así también, en $13(16,7 \%)$ pacientes del Grupo 1 se diagnosticó intolerancia a la lactosa a diferencia de $17(32,7 \%)$ del Grupo 2 ( $p<0,035)$. No hubo letalidad en los 130 pacientes que cursaron con rotavirosis.

Costos directos. Aplicados según arancel FONASA de atención cerrada (Anexo 1). El ítem que presentó mayor costo corresponde a la sumatoria de los días de hospitalización que alcanzó a \$ 8.973.750 (US 17.257)* en el Grupo 1 y \$ 6.461.100 (US 12.425) en el Grupo 2. (Tabla 4). La sumatoria de los costos evaluados: día cama, exámenes de laboratorio y agregando consulta de urgencia para el grupo 1, determinó un promedio total por caso de \$ 143.805 (US 277) en lactantes con diarrea por rotavirus de adquisición en la comunidad y un costo de \$139.423 (US 268) para lactantes con diarrea por rotavirus de adquisición nosocomial. El gasto directo total consumido por el Servicio de Pediatría a causa de esta infección intrahospitalaria fue de \$ 7.250.010 (US 13.900) (Tabla 4).

\section{Discusión}

Este estudio entrega aspectos desconocidos a la fecha en nuestra institución y en el país respecto del comportamiento de la diarrea por rotavirus en lactantes, ya sea de adquisición comunitaria o nosocomial, cual es un diagnóstico de situación de una patología de frecuente presentación en nuestra población hospitalaria. Con un total de 2.175 egresos de lactantes en los doce meses de estudio, se confirmó rotavirosis de adquisición comunitaria en 78 , determinando una tasa de 3,58 por 100 egresos. Sin embargo, dado el método diagnóstico empleado, (electroforesis), la pesquisa de casos se podría optimizar empleando mejores pruebas diagnósticas como detección de antígenos por test de ELISA cuya sensibilidad y especificidad son cercanas al $95 \%$, pruebas de aglutinación de látex o pruebas de biología molecular (RT-PCR), pero con evidente mayor costo económico.

El seguimiento efectuado demuestra la presencia de rotavirus en la comunidad la mayor parte del año, con una elevada incidencia de hospitalización en los meses de noviembre a febrero. Así también, se detecta la

\footnotetext{
*1 dólar americano $=520$ pesos (diciembre 2005)
}

existencia de casos de diarrea intrahospitalaria durante todo el año, identificándose claramente la presencia de un brote entre septiembre y octubre del año 2003, el que fuera posiblemente controlado por algunas medidas de intervención, pero sin lograr la desaparición total de posteriores casos nosocomiales.

Tabla 2. Tasas por mes y total por 100 egresos de diarrea nosocomial por rotavirus en lactantes hospitalizados. Servicio de Pediatría - Hospital Clínico San Borja Arriarán. Julio 2003 a junio 2004

\begin{tabular}{|c|c|c|c|}
\hline Mes & $\begin{array}{c}\text { Total egresos } \\
\text { (Lactantes)* }\end{array}$ & $\begin{array}{c}\mathbf{N}^{\circ} \text { diarreas } \\
\text { RV }-\mathbf{I I H}\end{array}$ & $\begin{array}{c}\text { Tasa por } 100 \\
\text { egresos }\end{array}$ \\
\hline
\end{tabular}

$\begin{array}{llrl}\text { Año 2003 } & & & \\ \text { Julio } & 408 & 0 & 1,29 \\ \text { Agosto } & 387 & 5 & 5,75 \\ \text { Septiembre } & 226 & 13 & 2,89 \\ \text { Octubre } & 207 & 6 & 1,35 \\ \text { Noviembre } & 148 & 2 & 1,54 \\ \text { Diciembre } & 194 & 3 & \end{array}$

\begin{tabular}{lccc|}
\hline Año 2004 & & & \\
Enero & 64 & 4 & 6,25 \\
Febrero & 41 & 2 & 4,87 \\
Marzo & 72 & 4 & 5,55 \\
Abril & 84 & 1 & 1,19 \\
Mayo & 139 & 6 & 4,31 \\
Junio & 205 & 6 & 2,92 \\
& 2.175 & $\mathbf{2}, 39$ \\
\hline Total & & \\
\hline * Fuente Departamento de Estadística, Hospital Clínico San Borja Arriarán. & \\
\hline
\end{tabular}

Tabla 3. Distribución de lactantes con diarrea por rotavirus (RV) según puntaje de gravedad de gastroenteritis*. Servicio de Pediatría. Hospital Clínico San Borja Arriarán. Julio 2003 a junio 2004

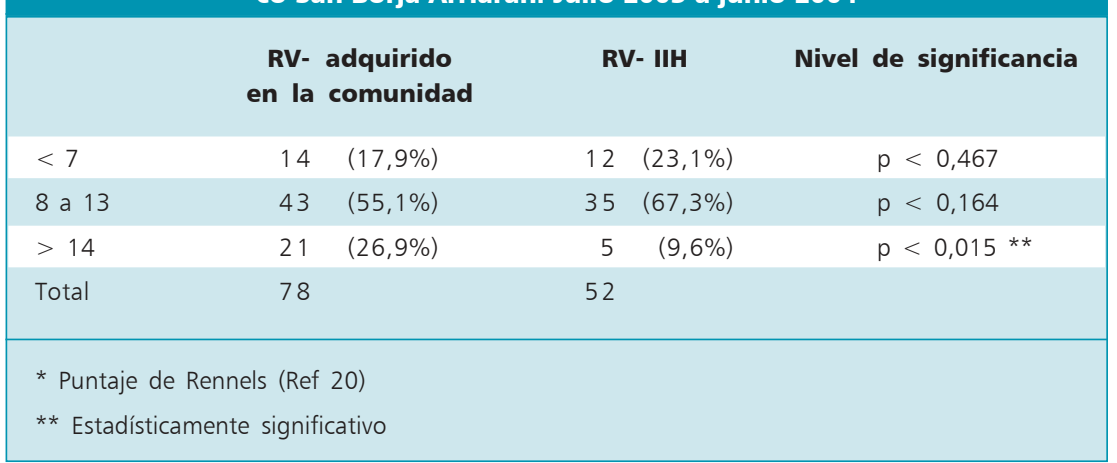


Tabla 4. Costos directos según ítem de gasto en rotavirosis. Servicio de Pediatría - Hospital Clínico San Borja Arriarán. Julio 2003 a junio 2004. $(n=130)$

\begin{tabular}{|c|c|c|c|c|c|c|}
\hline \multirow[t]{2}{*}{ Prestación hospitalaria } & \multicolumn{3}{|c|}{$\begin{array}{l}\text { RV de adquisición comunitaria } \\
\qquad(n=78)\end{array}$} & \multicolumn{3}{|c|}{$\begin{array}{l}\text { RV nosocomial } \\
(n=52)\end{array}$} \\
\hline & Cantidad & Costo $\$$ & Costo US & Cantidad & Costo $\$$ & Costo US \\
\hline Consulta en Urgencia & 78 & 636.480 & & -—— & & \\
\hline Días estadía hospitalaria & 375 & 8.973 .750 & 17.257 & 270 & 6.461 .100 & 12.425 \\
\hline Hemograma & 85 & 137.700 & 264,8 & 37 & 59.940 & 115,2 \\
\hline Proteína $C$ reactiva & 73 & 240.900 & 463 & 41 & 135.300 & 260 \\
\hline Gases en sangre & 214 & 430.140 & 827 & 76 & 152.760 & 294 \\
\hline Electrolitos plasmáticos & 219 & 144.540 & 278 & 77 & 50.820 & 97,7 \\
\hline Glicemia & 38 & 26.980 & 51,9 & 4 & 2.840 & 5,5 \\
\hline Nitrógeno ureico & 45 & 31.950 & 61,4 & 9 & 6.390 & 12,3 \\
\hline Perfil bioquímico & 25 & 114.000 & 219,2 & 14 & 63.840 & 122,8 \\
\hline Inmunofluorescencia viral & 7 & 19.460 & 37,4 & 3 & 8.340 & 16 \\
\hline Orina completa & 32 & 22.720 & 43,6 & 17 & 12.070 & 23,2 \\
\hline Hemocultivo & 12 & 27.360 & 52,6 & 8 & 18.240 & 35 \\
\hline Coprocultivo & 53 & 119.250 & 229,3 & 38 & 85.500 & 164,4 \\
\hline Urocultivo & 26 & 51.220 & 98,5 & 17 & 33.490 & 64,4 \\
\hline Cultivo LCR & 2 & 3.180 & 6,1 & 1 & 1.590 & 3 \\
\hline Rotaforesis & 81 & 225.180 & 433 & 52 & 144.560 & 278 \\
\hline Ph - Fehling en deposiciones & 19 & 11.970 & 22,8 & 21 & 13.230 & 25,4 \\
\hline Total & & 11.216 .780 & 21.570 & & 7.250 .010 & 13.942 \\
\hline Total por caso & & 143.805 & 276 & & 139.423 & 268 \\
\hline
\end{tabular}

Llama la atención que $56,8 \%$ de los pacientes con diarrea nosocomial fueron lactantes bajo 6 meses de edad, comparado la edad observada en los internados por rotavirosis adquirida en la comunidad $(20,5 \%$ bajo 6 meses $)(p<0,0001)$ factor de riesgo que podría explicarse por el mayor número de atenciones clínicas que estos lactantes demandan dentro del hospital, y por consiguiente mayor posibilidad de contener otros agentes infecciosos de los pacientes de su entorno vía mano portada. En el grupo de diarrea adquirida en la comunidad, 79,5\% se ubicó entre 7 y 24 meses de edad, siendo un factor a considerar en esta edad la disminución de lactancia materna como fuente de alimentación exclusiva, administrándose alimentos que requieren de mayor manipulación.

Es importante también destacar que $56,8 \%$ de los lactantes iniciaron su episodio de rotavirosis nosocomial entre el $3^{\circ}$ y $5^{\circ}$ día de internación. En ello podría incidir el frecuente cambio de sala que experimentan los pacientes los primeros días desde la Unidad de Ingresos, en ausencia de salas habilitadas para pa- cientes con diarrea que mantengan los insumos necesarios y la supervisión permanente de las prácticas de atención frente a estos pacientes.

Los lactantes que se hospitalizan por diarrea aguda, corresponden sólo a un pequeño porcentaje de los pacientes que contraen la enfermedad en la comunidad, aquellos que presentan signos y síntomas de mayor gravedad, lo que determina un sesgo al compararlos con los casos de diarrea nosocomial por rotavirus. Los lactantes con rotavirosis adquirida en la comunidad presentaron con mayor frecuencia fiebre sobre $40{ }^{\circ} \mathrm{C}(\mathrm{p}<0,04)$, una significativa mayor acidosis metabólica manifiesta por el nivel de bicarbonato de sodio plasmático promedio $(14,8 \mathrm{mEq} / 1$ versus $19 \mathrm{mEq} / 1, \mathrm{p}<0,001)$, shock hipovolémico o necesidad de expansión de volumen intravascular por inestabilidad hemodinámica (20 casos en el Grupo 1 y 5 casos en el Grupo 2) $(\mathrm{p}<0,023)$ y finalmente, mayor gravedad según la escala de puntuación empleada $(26,9 \%$ de pacientes del Grupo $1>$ a 14 puntos en comparación a $9,6 \%$ en el Grupo 2) ( $p<0,015)$, indicadores que no 
difieren mayormente de lo publicado en la literatura extranjera $^{23,24}$. Evidentemente, estos son valores esperables en pacientes que inician y/o cursan una infección intrahospitalaria donde recibirán atención y control diferente a aquel que cursa sus primeras horas de evolución en su domicilio, y de paso explicarían la menor indicación de hidratación parenteral en pacientes con infección nosocomial (46,2\% sin apoyo de fleboclisis), privilegiándose la hidratación oral o por gastroclisis en forma precoz. No obstante, es importante reconocer que un pequeño grupo de pacientes con infección nosocomial, a pesar de estar controlados por el equipo de salud, puede presentar una deshidratación que requiera de medidas de reanimación específicas.

Las tasas mensuales o anuales observadas en nuestra experiencia, por sobre el indicador nacional de diarrea intrahospitalaria en lactantes, confirman una deficiencia en las medidas de prevención y control de infecciones nosocomiales aplicadas en este servicio pediátrico. Si bien es cierto las medidas recomendadas incluyen el empleo de precauciones de contacto y enfatizan el lavado de manos con programas activos de supervisión, el control de fomites, reconocidos elementos de riesgo en la transmisión de rotavirus, (su presencia en teléfonos, fuentes de agua, lavamanos ${ }^{25}$ y también en juguetes como fuente de brotes nosocomiales, $\operatorname{etc}^{26}$ ), deben ser vigilados.

La importancia del lavado de manos, aunque la evidencia es circunstancial por dificultades en lograr un diseño de estudio controlado, se apoya en la sobrevida de este agente patógeno en las manos del personal de salud (por más de 4 horas y con mejor sobrevida que algunos virus respiratorios) y algunas superficies ambientales permitiendo entonces su transferencia de un paciente a otro, y activando la cadena de transmisión ${ }^{17,18}$.

Además, se describe que este agente viral infeccioso es relativamente resistente a la mayoría de los jabones comúnmente empleados para el lavado de manos y también a antisépticos habituales empleados en los hospitales a no ser que se preparen en conjunto con alcohol $70 \%{ }^{23}$. Esta afirmación, se basa en una publicación de Ansari en $1989^{27}$ quien después de infectar con una suspensión fecal con rotavirus o E. coli manos y dedos de adultos voluntarios, los sometió a lavados con diferentes productos, evaluando posteriormente el porcentaje de reducción de estos agentes. En estas condiciones se observó reducción de rotavirus en $99,9 \%$ de las manos si se utilizaba alcohol a 70\%; $98,9 \%$ de las manos al usar clorhexidina con alcohol; $84,8 \%$ de las manos y $78 \%$ de los dedos lavados con clorhexidina al 1,5\%; reducción del $86,9 \%$ en los dedos al emplear jabón líquido corriente y $85,5 \%$ de las manos al lavarse con agua corriente.
La práctica del lavado de manos en unidades no críticas de los hospitales en Chile, incluido el servicio en donde se efectuó este estudio, por lo general considera el empleo de jabones corrientes, ocasionalmente clorhexidina, constituyendo entonces los jabones en base alcohólica un elemento a considerar como política de intervención en prevención de estas infecciones cruzadas; seguramente las autoridades sanitarias requerirán de un estudio de efectividad dado su mayor costo. Otros factores como la eliminación de rotavirus en deposiciones en etapa pre sintomática, y el número de niños asintomáticos que también eliminan rotavirus, aunque pudieran ser importantes en la transmisión, no fueron evaluados.

El diagnóstico de intolerancia a la lactosa efectuado a $32,7 \%$ de los pacientes con diarrea nosocomial en comparación a $16,7 \%$ de los pacientes que contrajeran la rotavirosis en la comunidad $(p<0,035)$, pudiese estar influenciado quizás por co-morbilidades existentes en los pacientes con infección nosocomial y tal vez porque su búsqueda se efectuó en $24,3 \%$ de los pacientes del grupo con infección extrahospitalaria en contraste con la solicitud de este examen en 40,3\% de los pacientes con diarrea intrahospitalaria.

Por último, la evaluación de costos efectuada tiene que ser valorada cuidadosamente, ya que independientemente de que pudiesen impresionar como subvaloradas, corresponden a los valores asignados a las diferentes prestaciones de FONASA en atención cerrada y son aplicables a los diferentes centros hospitalarios públicos y sabemos que distan de acercarse siquiera a los valores de centros privados, en los que este valor sobrepasa apenas el valor asignado por un día cama de hospitalización sin considerar insumos, apoyo de laboratorio ni honorarios. Además se excluyó otros costos como por ejemplo el valor de transporte para visitas del menor hospitalizado, el costo de alimentación de la madre, el costo de las licencias médicas originadas y la pérdida de días laborales cuando así correspondiese.

Con todo, la suma de los gastos de consulta en Servicio de Emergencia para los lactantes con rotavirosis adquirida en la comunidad, días de estadía hospitalaria y exámenes de laboratorio en todos los pacientes entrega un valor, desconocido a la fecha en el país, sin mayores diferencias de $\$ 143.805$ (US 277) para el grupo 1 y $\$ 139.423$ (US 268) para pacientes con rotavirosis nosocomial, cifras no despreciables sobre todo cuando el costo total originado en doce meses por esta infección intrahospitalaria con valor de $\$ 7.250 .010$ (US 13.900), pudiese ser aminorado y significar a futuro ahorro para el servicio pediátrico con un efectivo y supervisado programa de intervención. Estos valores además, debieran ser considerados al mo- 
mento de evaluar el próximo ingreso de una vacuna contra rotavirus en el país.

\section{Resumen}

Este estudio observacional prospectivo describe elementos clínicos y costos directos de lactantes hospitalizados (julio 2003 a junio 2004), con diarrea confirmada por rotavirus de adquisición comunitaria $(\mathrm{G}-1, \mathrm{n}=78)$ y otros de adquisición nosocomial $(\mathrm{G}-2, \mathrm{n}=52)$. Se les aplicó una escala de gravedad de gastroenteritis, según Rennels 1996, de 0 a 17 pun- tos y asignó costos directos según arancel FONASA. Un $26,9 \%$ de pacientes del G-1 tuvo puntaje > a $14 v / s \quad 9,6 \%$ del G-2 $(p<0,015)$. Así también los lactantes del G-1 presentaron menor nivel de bicarbonato plasmático $(\mathrm{p}<0,001)$ y mayor frecuencia de shock o requerimiento de expansión de volumen $(\mathrm{p}<0,023)$. El costo promedio total fue de $\$ 143.805$ (US 277) para un caso de rotavirosis adquirida en la comunidad y $\$ 139.423$ (US 268) para la de origen nosocomial. Hubo un gasto de $\$ 7.250 .010$ (US 13.900) en esta infección nosocomial, lo que amerita la implementación de un programa activo de prevención y control.

\section{Referencias}

1.- Navarrete S, Muñoz O, Santos I. Infecciones Intrahospitalarias en Pediatría. Editorial McGraw-Hill Interamericana, México 1998.

2.- Otaiza F, Brenner P. Informe de Vigilancia Epidemiológica de las Infecciones Intrahospitalarias 1999-2000. Ministerio de Salud. Gobierno de Chile.

3.- Donowitz L. Hospital-acquired infections in children. N Engl J Med 1990; 323: 1836-7.

4.- Ratner A, Neu N, Jakob K, Grumet $S$, Adachi N, Della-Latta P, et al. Nosocomial rotavirus in a pediatric hospital. Infect Control Hosp Epidemiol 2001; 22: 229- 301.

5.- Harris J. Pediatric nosocomial infections : children are not little adults. Infect Control Hosp Epidemiol 1997; 18: 739-42.

6.- Raymond J, Aujard Y. Nosocomial infections in pediatric patient: A European, multicenter prospective study. Infect Control Hosp Epidemiol 2000; 21: 260-3.

7.- Brenner P, Pohlenz M, Otaiza F. Informe de Vigilancia Epidemiológica Infecciones Intrahospitalarias Chile 2002. Ministerio de Salud, Gobierno de Chile.

8.- Parashar VD, Hummelman EG, Breesee JS, Miller MA, Glass RI. Global illness and deaths caused by rotavirus disease in children. Emerg Infect Dis 2003; 9: 565-72.

9.- O'Ryan M, Perez-Schael I, Mamani N, Peña A, Salinas B, González G, et al. Rotavirus-associated medical visits and hospitalizations in South America: a prospective study at three large sentinel hospitals. Pediatr Infect Dis J 2001; 20: 685-93.

10.- Glass R, Kilgore P, Holman R, Jin S, Smith J, Woods P, et al. The epidemiology of rotavirus diarrhea in the United States: surveillance and estimates of disease burden. J Infect Dis 1996; 174: S5-S11.

11.- Bishop R, Barnes G, Cipriani E, Lund J. Clinical immunity after neonatal rotavirus infection: a prospective longitudinal study in young children. N Engl J Med 1983; 309: 72-6.

12.- Matson D, Estes M. Impact of rotavirus infection at a large pediatric hospital. J Infect Dis 1990; 162: 598-604.

13.- Pickering L, Woodward W. Diarrhea in day care centers. Pediatr Infect Dis 1982; 1: 47 52.

14.- Pickering L, Bartlett A, Reves P, Morrow A. Asymptomatic excretion of rotavirus before and after rotavirus diarrhea in children in day care centers. J Pediatr 1988; 12: 361-5.

15.- Richardson S, Grimwood K, Gorelli R, Palombo E, Barnes G, Bishop R. Extended excretion of rotavirus after severe diarrhoea in young children. Lancet 1998; 351: 1844 8.

16.- Butz A, Fosarelli P, Dick J, Cusack T, Yolken R. Prevalence of rotavirus on high risk fomites in day-care facilities. Pediatrics 1993; 92: 202-5.

17.- Dennehy P. Transmission of rotavirus and other enteric pathogens in the home. Pediatr Infect Dis J 2000; 19: S 103-5.

18.- Ansari S, Springthorpe S, Sattar S. Survival and vehicular spread of human rotaviruses: possible relation to seasonality of outbreaks. Rev Infect Dis 1991; 13: 448-61.

19.- Kalica AR, Sereno MM, Wyatt G, Mebus CA, Chanock RM, Kapikian AZ. Comparison of human and animal rotavirus strains by gel electrophoresis of viral RNA. Virology 1978; 87: 247-55.

20.- Rennels M, Glasss R, Dennehy P, Bernstein D, Pichichero M, Zito E, et al. Safety and efficacy of high dose rhesus human reassortant rotavirus vaccines. Report of the national multicenter trial. Pediatrics 1996; 97: 7-13.

21.- Flores J, Pérez-Schael I, González M, García D, Perez M, Daoud N, et al. Protection against severe rotavirus diarrhoea by rhesus rotavirus vaccine in Venezuelan infants. Lancet 1987; 1: 882-4.

22.- Dennehy PH, Schutzbank TE, Thorne GM. Evaluation of an automated immunodiagnostic assay, VIDAS rotavirus, for detection of rotavirus in fecal specimens. J Clin Microbiol 1994; 32: 825-7.

23.- Frühwirth M, Heininger U, Ehlken B, Petersen G, Lauberau B, Moll-Shüler I, et al. International variation in disease burden of rotavirus gastroenteritis in children with community-and nosocomially acquired infection. Pediatr Infect Dis J 2001; 20: 784-91.

24.- Tapar N, Sanderson T. Diarrhoea in children: An interface between developing and developed countries. Lancet 2004; 363 : 641-53.

25.- Arlene B, Fosarelli P, Dick J, Cusack T, Yolken R. Prevalence of rotavirus on highrisk fomites in day-care facilities. Pediatrics 1993; 2: 202-5.

26.- Rogers M, Weinstock D, Eagan J, Keihn T, Armstrong D, Sepkowitz K. Rotavirus outbreak on a pediatric oncology floor: possible association with toys. Am J Infect Control 2000; 28: 378-80.

27.- Ansari S, Sattar S, Springthorpe S, Wells G, Tostowaryk W. In vivo protocol for testing efficacy of hand-washing agents against viruses and bacteria: experiments with rotavirus and Escherichia coli. Appl Environ Microbiol 1989; 55: 3113-8. 